\title{
Public support
}

for vegetarian

meals in public

canteens:

a preliminary study

Sónia Goulart Cardoso

Fábio Rafael Augusto

Nádia Carvalho Nunes

João Graça 


\section{INTRODUCTION}

In 2016 the United Nations implemented the 2030 Agenda for Sustainable Development with 17 Sustainable Development Goals and 169 targets pertaining to the economic, social, and environmental dimensions. Scientific evidence suggests that of the 17 goals, at least six would be closer to being accomplished $^{1}$ if the Global West transitioned to a more plant-based diet. ${ }^{2}$ In 2006 a FAO (Food and Agriculture Organization of the United Nations) report identified the livestock sector as "by far the single largest anthropogenic user of land" (Steinfeld et al. 2006, xxi) since it uses no less than $70 \%$ of all agricultural land and $30 \%$ of the land surface of the planet. This amount of production takes its toll on the environment: the livestock sector operates as a big influencer in climate change, reportedly responsible for $18 \%$ of greenhouse gas emissions - a share higher than all transports taken together. The sector is also stated to be one of the greatest contributors to water pollution and biodiversity loss (possibly even being the primary cause) due to its role in deforestation and in "land degradation, pollution, climate change, overfishing, sedimentation of coastal areas and facilitation of invasions by alien species" (Steinfeld et al. 2006, xxii and xxiii).

Part of the solution is to transition toward more plant-based diets since these types of diet tend to generate less waste, preserve more water, and exert significantly less toll on the land and soil (Marlow et al. 2009). As consumption of animal products rises with income, a higher intake is commonly found in developed countries, where a significant part of the population consumes an unnecessary amount of animal protein. According to Smil (2002), the production of a typical Western diet requires up to $4000 \mathrm{~m}^{2}$ of agricultural land per capita, meaning that if the whole world followed the Western dietary pattern, the existing agricultural land would not suffice.

1 The six relevant goals are: "End hunger, achieve food security and improved nutrition and promote sustainable agriculture"; "Ensure availability and sustainable management of water and sanitation for all"; "Ensure sustainable consumption and production patterns'; 'Take urgent action to combat climate change and its impacts"; "Conserve and sustainably use the oceans, seas and marine resources for sustainable development"; "Protect, restore and promote sustainable use of terrestrial ecosystems, sustainably manage forests, combat desertification, and halt and reverse land degradation and halt biodiversity loss"(un General Assembly 2015).

2 Plant-based diets are diets that limit or avoid animal sources and have the bulk of calories from plant sources, such as vegetarian diets (Graça, Oliveira, and Calheiros 2015; Stehfest et al. 2009). 
PORTUGUESE TRENDS REGARDING DIETARY PATTERNS AND SUSTAINABLE EATING HABITS

Dietary patterns in Portugal compare to those of the Global West, being high in animal products and caloric intake. Data from the National Institute of Statistics shows that in 2012-2016, the Portuguese intake of meat, fish, and eggs exceeded the recommendations - instead of the recommended $5 \%$, these protein sources reached an equivalent of $16 \%$ of the Portuguese diet in 2016 (Instituto Nacional de Estatística 2017). Nevertheless, the Portuguese health authorities released guidelines for healthy vegetarian diets for adults and children, stressing that the country's abundance in vegetable products all year around makes for a smooth transition to plant-based diets (Direção-Geral da Saúde 2016).

In 2016 a partnership between ICS-UL (Institute of Social Sciences of the University of Lisbon) and Missão Continente (a social responsibility programme held by a major national supermarket chain) developed the first national survey to analyse the Portuguese population values, knowledge, and representations of sustainability in its various dimensions, including diet. Although the vast majority recognized the benefits of eating plenty of fruit and vegetables, only $33.3 \%$ identified reducing red meat consumption as important to maintaining healthy eating habits. Furthermore, when asked about their willingness to eat more vegetable proteins instead of meat, $45 \%$ answered favourably, while $16.8 \%$ were uncertain, and $38.1 \%$ were unwilling to do so.

Nevertheless, while an estimated $95 \%$ of the Portuguese population eats animal products (meat, fish, dairy, and eggs), plant-based diets are increasing in popularity. A 2017 survey set to determine the growth of vegetarianism has concluded that $1.2 \%$ of the Portuguese population currently follows a vegetarian diet, a fourfold increase since 2007 (Centro Vegetariano 2017).

SUSTAINABLE LIFESTYLES ON THE SPOT: EMERGING SOCIETAL CHANGES

Across the globe, citizens' concern about environmental sustainability has been increasing over the last years (National Geographic and GlobeScan 2014). Since food consumption is relevant for environmental sustainability, those concerns could be triggering changes in the food system and, indeed, advances are slowly being made. Examples are the 2016 dietary guidelines 
published by the Chinese Government outlining a plan to reduce its citizens' meat consumption by $50 \%$, and the meat tax discussion in Denmark's Parliament to help combat climate change (Milman and Leavenworth 2016; Nagesh 2016).

Similarly, plant-based diets are also increasingly under the spotlight across several segments of society. For instance, Danish politicians are joining vegan challenges to serve as role-models and Helsinki and other Finnish cities declared a mandatory weekly vegetarian day in schools (Lombardini and Lankiski 2013; Morley 2017;). In 2006, vegetarian food was considered a hot trend by the famous Baum+Whiteman food consultants group and the influential power of celebrities advocating a plant-based diet (such as Bill Clinton or Ellen DeGeneres) has likely contributed to raising awareness of the topic. The buzz also reached the economic sector, with the accelerated growth of the value of the vegetarian food market from $£ 333$ million in 1996 to $£ 786.5$ million in 2011 (more information on www.miltel.com).

In Portugal the large majority of citizens show a great deal of concern pertaining to the health consequences of meat consumption (Schmidt et al. 2016) and recent empirical data show an increasing demand for organic products in the country (Truninger 2010). The economic sector seems amenable to these tendencies, and the main supermarket chains in the country are now offering health-conscious sections in their stores, including animalfree and organic products (Nunes and Pereira 2016).

\section{NEW POLICIES ON TRANSITIONING TOWARD SUSTAINABLE EATING}

The widespread availability of more sustainable food options and the boom of meat reduction initiatives are being followed by requests to develop food policies that promote a more plant-based diet. For the purposes of our work, we will refer to food policy as any plan, guideline, regulation, or course of action created by the government and adopted by institutions and/or citizens to guide choices, decisions, and/or actions concerning the food system (Obenchain and Spark 2016). In a nutshell, any policy that affects "who eats what, when, how, and with what impact” (Obenchain and Spark 2016, 4).

In 2008 Roots of Change (an American food activist organization) developed a Declaration for Healthy Food and Agriculture, "meant to provide policymakers with a set of principles, endorsed by a broad base of organizations and individuals committed to a healthier food and agriculture, to use in creating 
policy that will lead to a healthier food system" (Obenchain and Spark 2016, 121). Efforts for changes in the European Union food policy are also being requested. For instance, the Planting Fresh Ideas movement brings together citizens, corporations, and policy makers to achieve a reduction of $30 \%$ on the EU consumption of animal-based foods by 2030 (more information on their website, www.plantingfreshideas.eu/). Additionally, policy makers seem receptive to working together with researchers. For instance, the European Roundtable on Sustainable Consumption and Production (ERSCP) society was created to be a non-profit forum providing a platform of academics as well as practitioners to stimulate, develop, and disseminate new initiatives aimed at fostering the implementation of sustainable consumption and production.

In Portugal a recent law based on environmental, health, and animal protection concerns made vegetarian options mandatory in all public canteens (prisons, hospitals, schools, and elderly care centres) - Law n. ${ }^{\circ} 11 / 2017$. The legislative proposal $n .^{\circ} 111 /$ XIII (2006) was proposed by the political party PAN (People - Animals - Nature) and pointed out some of the problems of the current food system, the increasing adherence to plant-based diets, and the benefits of these diets. In June 2017 the law began to be implemented, giving six months to public canteens to be fully prepared to serve vegetarian options.

Although vegetarianism has been considered a blossoming field of research (Ruby 2012), literature approaching the ramification of this field into policy support, legal change, or social movements is scarce. Only recently have researchers started to explore which variables could be linked to citizens' support for policies that promote plant-based diets (Whitley, Gunderson and Charters 2017). As such, literature regarding worldviews could be particularly highlighting.

\section{WORLDVIEWS AND POLICY SUPPORT}

Sustainable behaviours are deeply embedded in worldviews, values, and cultural associations and habits (Soron 2010). Worldviews are sets of beliefs and assumptions that attempt to establish a complete and coherent view of how the world operates (Cobern 1996). Worldviews embody values (that are one of several types of beliefs) but can also include other types of beliefs (Koltko-Rivera 2004).

The "collated model of worldview" proposes 40 dimensions that deal with a different topic of worldview beliefs (Koltko-Rivera 2004). One of them refers 
to the relationship between humanity and the natural world. It profoundly influences perceptions of the proper human-environment relationship, positing humanity in a subjugation, mastery, or equilibrium point regarding nature.

This set of beliefs constitutes a framework that may have powerful effects on cognition and behaviours, for instance, on the adoption of sustainable lifestyles. Take for example the consumption of organic food. The beginning of organic agriculture in the 2oth century has frequently been associated with shifting views on and feelings toward nature. Such changing perspectives on the humannature relationship - from domination over nature toward participation with nature - may point at larger processes of changing worldviews in society, thereby supporting economic and political trends, such as global growth in the organic food industry or the emergence of political support for organic agriculture. In fact, worldviews not only shape how individuals perceive particular issues and their potential solutions, they also tend to influence their willingness to partake in such solutions themselves, as well as their political support for addressing the issue societally (Gifford 2011).

One of the most widely used scales measuring worldviews concerning sustainability and environmental concern is the NEP scale (New Ecological Paradigm; Dunlap et al. 2000). Given its relevance to the present work, we describe it in detail in the next section.

\section{MEASURING ENVIRONMENTAL CONCERN: THE NEP SCALE}

Until the 1970s the "Dominant Social Paradigm" (DSP; Pirages and Erhlich 1974) was a belief in economic growth, progress, and unlimited natural resources and humans were seen as above and independent from nature. Since then a new set of ideas rooted in environmental awareness has challenged the DSP by proposing that nature cannot support unlimited economic growth. Human activity and nature were seen as inextricably interconnected and, therefore, the fragile equilibrium of nature could be disturbed by humans' behaviours. Dunlap and Van Liere (1978) were interested in measuring these new ideas and developed the first version of the "New Environmental Paradigm" (NEP), not knowing that it would become one of the most widely used scales to explore environmental worldviews in the following decades. According to Dunlap $(2008,10)$ the scale measured an "ecological worldview", the overall relationship between humans and the environment. Those generalized beliefs about the nature of human-environment interactions may be influenced by 
social structure and values, which could, in turn, influence attitudes, beliefs, and behavioural intentions regarding environmental issues (Stern, Dietz and Guagnano 1995).

Twenty-two years later, Dunlap and colleagues (2000) recognized several limitations of the original New Environmental Paradigm Scale and proposed an updated scale, termed the New Ecological Paradigm (NEP) Scale. This new scale comprises 15 items that tap a wider range of facets of an ecological worldview and offer a balanced set of pro- and anti-NEP statements (Dunlap et al. 2000).

Although Dunlap (2008) highlighted that the NEP is "a broad attitude measure" and was not intended to predict specific behaviours, several authors have found the NEP scale to be a useful predictor of both reported and observed behaviour and included it as a key variable in theoretical models developed to predict environmental behaviours (Stern, Dietz and Guagnano 1995). For instance, the NEP could predict pro-environmental behaviours such as recycling, using public transports, buying organic food, and environmental activism, such as boycotting products or donating money to support an environmental cause (Blake, Guppy and Urmetzer 1997)

More important for the purposes of our study, it also predicts several kinds of policy support. For instance, Rauwald and Moore (2002) concluded that the NEP scale was a good predictor of policy support for tax incentives for voluntary land protection, stricter environmental regulation of public lands, and protection of natural parks despite reduced hunting and timber opportunities (for the American sample). Moreover, Milfont, Hawcroft, and Fischer (2008, cited in Dunlap 2008) found that national-level NEP scores were positively related to nations' endorsement of international environmental treaties.

Recently, Whitley, Gunderson, and Charters (2017) showed that the NEP is associated with higher levels of support for policy measures promoting plantbased diets. Additionally, individuals who value more equality and social justice were also more willing to support those kinds of policy measures. That is, individuals who were guided by concerns about others and nature were more receptive. The authors argued that support for policies, including those that promote plant-based diets and meat reduction, are rooted in individual's values, beliefs, and norms. Interestingly, these authors also tested the influence of eating practices on the support for policy measures that promote plantbased diets. They found that the consumption of vegetables has a positive influence on policy support; however, the consumption of red meat and eggs reduces policy support. 
By testing different types of variables, Whitley and colleagues (2017) were able to achieve a broader perspective about public receptiveness to policies promoting plant-based diets. Their work suggests that how we perceive others and what we eat, are also important predictors of how much we are willing to support policy measures linked with dietary choices. Ultimately, dietary choices influence our group membership and constitute building blocks of our own identity (Greenebaum 2012). As such, recent theorizing and research relating social psychology and vegetarianism could be relevant to our discussion. Theories regarding social groups are being applied to analyse the relationship between vegetarians and non-vegetarians, as we argue in the next section.

\section{MEAT CONSUMPTION AND VEGETARIANISM THREAT}

Despite the growing scientific consensus on the health and environmental benefits of shifting to more plant-based diets (in which vegetarian diets are typically included), large groups of consumers do not seem willing to change their habits (Graça, Oliveira and Calheiros 2015). The European Vegetarian Union estimated that vegetarians represent $2 \%$ to $10 \%$ of the total European population (Heinrich-Böll-Stiftung and Friends of the Earth Europe 2014). As mentioned above, in Portugal vegetarians still represent a fringe of the total population $(1.2 \%)$.

Seen as minorities, vegetarians are more prone to suffer discrimination and being perceived as symbolic threats to the integrity of prevailing social values and traditions in the Western society, in which the exploitation of animals is mainstream and cultural norms favour meat-eating (MacInnis and Hodson 2015). Some scholars have even suggested the existence of "vegophobia" (Cole and Morgan 2011).

Intergroup relations researchers began to take interest in the topic and are applying psychology theories to understand why and how bias against consumers of a plant-based diet has come about (Dhont, Hodson and Leite 2016). For instance, the Integrated Threat Theory (Stephan and Stephan 2000) has been proven relevant to address this issue. This theory posits that, if an outgroup's beliefs, values or norms challenge those followed by an ingroup, they could be seen as threats to the ingroup's value and dominant position within society, leading to negative attitudes toward the outgroup (Riek, Mania and Gaertner 2006). In fact, MacInnis and Hodson (2015) found that vegetarians are targets of discrimination. Individuals that endorse carnistic ideologies and 
eat meat more frequently are more likely to perceive vegetarians as a threat and to support animal exploitative practices (Monteiro et al. 2017; Dhont and Hodson 2014).

\section{PRESENT STUDY}

Resolutions focusing directly on citizens' dietary choices, and therefore potentially influencing their own identity, could take advantage of public support to be implemented consensually and effectively. Thus, our general goal is to investigate factors that could influence citizens' support for policies aiming to promote plant-based diets, by offering more dietary choices to consumers. Despite the importance of this topic, the benefits of a global transition to a more plant-based diet have only recently started to be debated politically, and specific or country-based measures are still scarce and fragmented. The current debate around the implementation of Law n. ${ }^{0} 11 / 2017$ in Portugal provided us with a rich context in which to investigate these questions. In contrast to Whitley and colleagues' (2017) investigation, we were interested in measuring citizens' support for a law that is actually being implemented (instead of hypothetical political measures).

We aimed to examine the extent to which citizens' support for a vegetarian option in public canteens is influenced by a set of beliefs and individual variables. Specifically, we assessed how support for a vegetarian option relates with personal views concerning the environment (i.e., New Environmental Paradigm), meat-eating habits, and perceived vegetarian threat.

Although research about policies promoting a plant-based diet is at an embryonic stage, the literature about environmental policy is more robust and previous studies have highlighted that several attitudinal, personal, and contextual variables are relevant predictors of citizens' willingness to support protective environmental policies (Zahran et al. 2006). One factor that has shown to be particularly important is the "ecological worldview", which establishes the type of relationship between humans and nature (Dunlap 2008). Recent research has also showed positive relationships between the support for several policies promoting a plant-based diet and the NEP scale, concluding that citizens' support for food policies is rooted in their worldview beliefs (Whitley, Gunderson and Charters 2017).

As we discussed above, research has also shown that those who hold ideologies contrasting with vegetarian beliefs, values, and eating choices, are 
more likely to perceive vegetarianism as a threat to the current norms and culture of Western societies. Thus, we expect that those who eat meat more frequently and those who construe vegetarianism as a threat to dominant social values would be less likely to support policies that somehow favour vegetarians, such as the inclusion of a mandatory vegetarian option in public canteens.

\section{METHOD}

\section{SAMPLE AND PROCEDURE}

The survey was hosted online by Qualtrics.com during August and September of 2017. Participants were recruited via ads in social media. A short recruitment notice invited users to participate in a study on "people's opinions about several issues such as the environment and eating habits". Participation was rewarded with the choice of registering in a draw to win a $50 €$ gift coupon. To minimize self-selection biases, no references were made in the advertisements and cover page to the specific goals of the study. Before beginning the survey, participants were informed about the study's procedures and assured that no individual answers would be analysed or reported. They were also informed that participation was entirely anonymous and voluntary. Participants provided their consent and were debriefed at the end of the study. A total of 318 participants (aged between 18 and 69 years, $M=28.77, S D=8.75$; 84 men) completed all the measures under analysis, most had completed secondary or higher education (23.7\% and $69.4 \%$, respectively), and nearly four fifths reported eating meat at least once in a regular week (i.e., 78.3\%).

\section{MATERIALS}

We assessed factors associated with support for a vegetarian option in canteens and cafeterias, namely, environmental concern, meat eating habits, and perceived vegetarian threat. At the end of the survey participants provided demographic information (age and gender) and their diet (omnivore, vegetarian, or other).

EnvironmentalConcern. We used thelastversion of the New Ecological Paradigm scale (Dunlap et al., 2000), which includes 15 items. Participants show their 
agreement, on a 5-point Likert scale ( 1 =I strongly disagree; 5 = I strongly agree) with the following sentences: (1) We are approaching the limit of the number of people the earth can support; (2) Humans have the right to modify the natural environment to suit their needs; (3) When humans interfere with nature it often produces disastrous consequences; (4) Human ingenuity will ensure that we do not make the earth unlivable; (5) Humans are severely abusing the environment; (6) The earth has plenty of natural resources if we just learn how to develop them; (7) Plants and animals have as much right as humans to exist; (8) The balance of nature is strong enough to cope with the impacts of modern industrial nations; (9) Despite our special abilities humans are still subject to the laws of nature; (10) The so-called "ecological crisis" facing humankind has been greatly exaggerated; (11) The earth is like a spaceship with very limited room and resources; (12) Humans were meant to rule over the rest of nature; (13) The balance of nature is very delicate and easily upset; (14) Humans will eventually learn enough about how nature works to be able to control it; (15) If things continue on their present course, we will soon experience a major ecological catastrophe. A pro-ecological view is represented by agreement with the odd-numbered items and disagreement with the evennumbered ones. As recommended by Dunlap (2008), we treated the items as a unidimensional scale and constructed a measure of Environmental Concern from the average of the items (Cronbach's $\alpha=.77$ ).

Meat Eating Habits. To assess participants' eating habits concerning meat, we asked them to indicate how often they consume white meat and red meat on a 5-point Likert scale ( 1 = never; 2 = less than a day a week; $3=$ once or twice a week; 4 = three or four days in a week; 5 = five or more days in a week).

Perceived Vegetarian Threat. We adapted the scale used by Dhont and Hodson (2014) to the Portuguese context: (1) The rise of vegetarianism poses a threat to our country's cultural customs; (2) Important culinary traditions which are typical to our country are starting to die out due to the rise of vegetarianism; (3) Eating meat is part of our cultural habits and identity and some people should be more respectful of that; (4) Vegetarians should have more respect for our traditional eating customs, which meat consumption is simply part of; (5) Important family traditions and celebrations are increasingly being ruined and disappearing because of the presence of vegetarians in certain families; (6) Vegetarianism has a negative influence on the Portuguese economy; 
(7) The vegetarian movement is too involved in local and national politics; (8) Nowadays, when it comes to nutrition and meals, people listen too much to what a minority of vegetarians wants. Participants indicated their agreement with statements on a 5-point Likert scale ( 1 = I strongly disagree; $5=$ I strongly agree). We constructed a Perceived Vegetarian Threat score corresponding to the average of the eight items (Cronbach's $\alpha=.88$ ).

Support for Vegetarian Option. Participants indicated how much they agree with the implementation of a policy measure promoting the offer of vegetarian meals in Portuguese public canteens and cafeterias, on a 5-point Likert scale (i.e., how much they agreed with the single-item "Ensuring that public canteens and cafeterias serve vegetarian meals"; $1=$ I strongly disagree; 5 = I strongly agree).

\section{RESULTS}

The descriptives for the variables under analysis (Table 12.1) show high levels of support for including a vegetarian option in public canteens $(M=4.51$ on a 5-point scale) in the current sample. The mean levels of Environmental Concern were also relatively high $(M=3.87$ on a 5 -point scale), whereas the variables referring to Meat Eating habits and Perceived Vegetarian Threat were closer to the mid-point of the scale $(M=2.90$ and $M=2.29$ respectively, on a 5 -point scale).

As for the correlations (Table 12.1), we expected that the variable Support for Vegetarian Option would show a positive association with Environmental Concern, and negative associations with Meat Eating habits and Perceived Vegetarian Threat. These predictions were largely confirmed. In other words, higher levels of support for including a vegetarian option in public canteens was associated with higher levels of environmental concern, and lower levels of meat consumption (both red meat and white meat) and perceived vegetarian threat. The correlations were still highly significant when controlling for age, gender, and diet (i. e. vegetarian vs. non-vegetarian) using partial correlations. This means that these associations hold true regardless of individual differences in terms of age, gender, and being or not being vegetarian.

The remaining variables also showed significant associations with each other. Specifically, Environmental Concern was negatively correlated with 
Table 12.1

Descriptives and correlations for the variables under analysis (i.e. Support for Vegetarian Option, Environmental Concern, Meat Eating habits, and Perceived Vegetarian Threat).

\begin{tabular}{|c|c|c|c|c|c|c|c|}
\hline & $\mathbf{M}$ & SD & $\mathbf{1}$ & 2 & 3 & 3.1 & 3.2 \\
\hline 1. Support for Vegetarian Option & 4.51 & .67 & - & & & & \\
\hline 2. Environmental Concern & 3.87 & .45 & $.27^{*}$ & - & & & \\
\hline 3. Meat Eating habits & 2.90 & 1.02 & $-.38^{*}$ & $-.38^{*}$ & - & & \\
\hline 3.1 Red meat & 2.62 & 1.12 & $-.36^{*}$ & $-.37^{\star}$ & - & - & \\
\hline 3.2 White meat & 3.21 & 1.21 & $-.30^{*}$ & $-.30^{*}$ & - & - & - \\
\hline 4. Perceived Vegetarian Threat & 2.29 & .76 & $-.37^{*}$ & $-.40^{*}$ & $.47^{*}$ & $.42^{*}$ & $.41^{*}$ \\
\hline
\end{tabular}

${ }^{*} \mathrm{p}<.001$.

Meat Eating habits and Perceived Vegetarian Threat. In turn, higher levels of meat eating were associated with higher levels of perceived vegetarian threat.

Next, we tested which variables accounted for more variance in support for a vegetarian option when including them together in the same model (Table 12.2). As discriminating between red and white meat did not yield differences in the patterns of associations (Table 12.1), to ensure parsimony we used the aggregate measure of meat eating habits in this model. The findings show that Environmental Concern, Meat Eating habits, and Perceived Vegetarian Threat together explained $20 \%$ of the variance in support for a vegetarian option. However, only Meat Eating habits and Perceived Vegetarian Threat were significant predictors in the model, which suggests that these variables together also account for the associations of Support for Vegetarian Option

Table 12.2

Linear regression for Environmental Concern, Meat Eating habits, and Perceived Vegetarian Threat in predicting Support for Vegetarian Option.

\begin{tabular}{lcccccc}
\multicolumn{1}{c}{ VARIABLES } & B & SE & B & R2 & F & DFS \\
\hline Model summary & & & & $.20^{*}$ & 25.25 & 3,315 \\
Environmental Concern & .14 & .09 & .09 & & & \\
Meat Eating habits & -.16 & .04 & $-.24^{*}$ & & & \\
Perceived Vegetarian Threat & -.19 & .05 & $-.22^{*}$ & & & \\
\hline
\end{tabular}


with Environmental Concern, which was observed in the preliminary correlational analysis.

Lastly, we also examined age, gender (male vs. female) and diet (veg vs. non-veg) differences in support for a vegetarian option. With regard to age, the association was weak and did not reach statistical significance $(r=-.10, n s)$. As for gender, although male participants $(N=83, M=4.41, S D=.77)$ showed lower absolute levels of support than female participants $(N=233, M=4.55, S D=.64)$, this difference was statistically small and non-significant $[t(314)=-1.68, n s$, Cohen's $d=-0.20]$. As for diet, as expected, vegetarian participants $(N=40$, $M=4.98, S D=.16$ ) showed higher levels of support than omnivorous (i.e., non-veg) participants $(N=230, M=4.42, S D=.71)$, and this difference was statistically large and significant $[t(268)=-4.93, p<.001$, Cohen's $d=-1.09]$. Nevertheless, both veg and non-veg participants showed high absolute levels of support for a vegetarian option in public canteens $(M=4.98$ and $M=4.42$, respectively, on a 5-point scale).

\section{DISCUSSION}

Since citizens are taking a more active role in demanding changes in policies promoting more sustainable approaches to food, research addressing this topic has gained importance in recent years. Thus, our preliminary study adds to the sustainability and policy support literature by analysing factors influencing public support for the implementation of a mandatory vegetarian option in the Portuguese public canteens. We took advantage of the current societal debate in Portugal to conduct a study centred on the actual implementation of a policy measure that was proposed resorting to sustainability motivations and aligned in an inclusion movement.

Our findings demonstrated that the current sample shows high levels of support for including a vegetarian option in public canteens. The law was grounded on principles of inclusion and proposed widening the range of options for the general public (independently of their dietary choices). Nevertheless, vegetarians showed higher levels of support (when compared to non-vegetarians). Our results do not allow us to make further inferences about this difference, and it would be useful if future research could assess the public's perceptions about the motivations associated with this law and its advantages/disadvantages. 
Regardless of their age, gender, and diet, higher levels of support were associated with higher levels of environmental concern, lower levels of meat consumption (both red meat and white meat), and perceived vegetarian threat. Thus, supporting the offer of a vegetarian option in public canteens is not only a result of environmental concern, it is also related with dietary group membership (vegetarian vs. non-vegetarian) and, ultimately, intergroup relations (perceived threat regarding other groups' beliefs).

Our results provide insights for developing strategies that could be applied before or after the implementation of food policies that promote the availability of more plant-based meals, in order to arguably increase their acceptance. For instance, if environmental concern is a key concept in the support for food policies that address plant-based diets, actions to increase the endorsement of the NEP could eventually contribute to how these policies are considered, respected, and encouraged. In this regard, Rideout (2005) showed that environmental concern could be increased by learning information about environmental problems. Thus, contextualized laws should be more effective in promoting societal adherence (Marteau 2017).

The Law $n .^{\circ} 11 / 2017$ could also influence the perceptions of canteen users regarding plant-based meals by contributing to greater exposure on such meals. Thus, it would be worthwhile for future research to more explicitly link the implementation of this law and possible effects on plant-based meals, perceived vegetarianism threat, feelings and perceptions about vegetarians, and even willingness to follow a more plant-based diet.

Future research could also measure other factors that may influence the level of public support for this law, considering the different phases of implementation. Our preliminary study was conducted in a very early phase, right after the approval of the law and its first massive dissemination by the media. By the end of 2017 , all public canteens must fulfill the adaptation period and canteen users should gain familiarity with vegetarian options (either by the simple exposure or through food practice). By then, it should be possible to examine more behavioural features of support (for instance, based on the number of vegetarian meals consumed) and explore associations with variables concerning ecological worldviews, intergroup relations, or identity.

Our study provides only a preliminary investigation that could inform further research. Limitations regarding our sample and the specific phase of the data collection do not allow us to make generalized assumptions. Thus, 
further studies should resort to a representative sample and address subsequent stages of implementation of this law.

It is important for scholars in the field of plant-based diets to keep a close eye on policy developments. Motivated either by sustainability issues, or just on the debate on dietary choices as a human right, policies that could somehow contribute to citizens' adherence to plant-based diets could be rooted in individuals' beliefs about human-nature relations and challenge the relations between groups with different dietary choices. The current findings suggest that these variables should be taken into account when studying public support for these types of food policies.

\section{॥ ACKNOWLEDGEMENTS}

Fábio Rafael Augusto wishes to gratefully acknowledge the financial support from the Portuguese Foundation for Science and Technology (FCT), under the PhD grant SFRH/ $\mathrm{BD} / 130072 / 2017$, co-funded by the European Social Fund (FSE) and national funds of the Portuguese Ministry of Science, Technology and Higher Education (мстеs) through the Human Capital Operational Programme ( $\mathrm{POCH})$.

SÓNIA GOULART CARDOSO

Instituto de Ciências Sociais, Universidade de Lisboa

Av. Prof. Aníbal Bettencourt 9-1600-036 Lisboa, Portugal

sonia.goulart.cardoso@ics.ulisboa.pt

orcid.org/oooo-0002-6442-5265

FÁBIO RAFAEL AUGUSTO

Instituto de Ciências Sociais, Universidade de Lisboa

fabio.augusto@ics.ulisboa.pt

orcid.org/oooo-0002-1957-2477

NÁDIA CARVALHO NUNES

Instituto de Ciências Sociais, Universidade de Lisboa

nadia.nunes@ics.ulisboa.pt

orcid.org/0ooo-0002-3927-5912

JOÃO GRAÇA

Instituto de Ciências Sociais, Universidade de Lisboa

joao.graca@ics.ulisboa.pt

orcid.org/oooo-0oo1-6868-9420 


\section{$\S \quad$ REFERENCES}

BLAKE, D. E., N. Guppy, and P. Urmetzer. 1997. "Canadian public opinion and environmental action". Canadian Journal of Political Science, 30: 451-472.

CENTRO VEgetARIANO. 2017. “120 ooo vegetarianos - Número duplica em 10 anos”. https://www.centrovegetariano.org/Article-620-Numero-vegetarianos-quadruplica-10anos-Po rtugal.html.

COBERN, W. 1996. "Worldview theory and conceptual change in science education". Science Education, 80 (5): 579-610.

COLE, M., K. Morgan. 2011. "Vegaphobia: derogatory discourses of veganism and the reproduction of speciesism in UK national newspapers". British Journal of Sociology, 62 (1): 134-153.

Dhont, K., G. Hodson, and A. Leite. 2016. "Common ideological roots of speciesism and generalized ethnic prejudice: the social dominance human-animal relations model (SD-HARM)". European Journal of Personality, 30 (6): 507-522.

DHONT, K., G. Hodson. 2014. "Why do right-wing adherents engage in more animal exploitation and meat consumption?". Personality and Individual Differences, 64: 12-17.

DIREÇÃo GERAL DA SAÚDE (DGS). 2016. Alimentação Vegetariana em Idade Escolar. Lisbon: Direção-Geral da Saúde.

DUNLAP, R., K. D. Van Liere. 1978. “The new environmental paradigm: a proposed measuring instrument and preliminary results". Journal of Environmental Education, 9 (4): 10-19.

DUNLAP, R. et al. 2000. "Measuring endorsement of the New Ecological Paradigm: a revised NEP scale". Journal of Social Issues, 56 (3): 425-442.

DUNLAP, R. 2008. “The new environmental paradigm scale: From marginality to worldwide use". Journal of Environmental Education, 40 (1): 3-18.

GIFFORD, R. 2011. "The dragons of inaction. Psychological barriers that limit climate change mitigation and adaptation". American Psychologist, 66 (4): 290-302.

GRAÇA, J., A. Oliveira, and M. M. Calheiros. 2015. "Meat, beyond the plate. Data-driven hypotheses for understanding consumer willingness to adopt a more plant-based diet". Appetite, 90 (1): 80-90.

GREENEBAUM, J. 2012. "Veganism, identity and the quest for authenticity". Food, Culture \& Society, 15 (1): 129-144.

HEINRICH-BÖLL-STIFTUNG AND FRIENDS OF THE EARTH EUROPE. 2014. "Meat atlas: facts and figures about the animals we eat", http://boell.de/en/meat-atlas.

instituto Nacional de estatística. 2017. Balança Alimentar Portuguesa 2012-2016. Lisbon: Instituto Nacional de Estatística.

Koltko-RIVERA, M. 2004. “The psychology of worldviews". Review of General Psychology, $8(1): 3-58$.

LOMBARDINI, K., L. Lankoski. 2013. "Forced choice restriction in promoting sustainable food consumption: intended and unintended effects of the mandatory vegetarian day in Helsinki schools". Journal of Consumer Policy, 36: 159-178.

MACINNIS, C. C., G. Hodson. 2015. "It ain't easy eating greens: evidence of bias toward vegetarians and vegans from both source and target". Group Processes \& Intergroup Relations, 20 (6): 1-24.

MARLOW, H. J., et al. 2009. "Diet and the environment: does what you eat matter?". The American Journal of Clinical Nutrition, 89: 1699S-1703S. 
MARTEAU, T. 2017. “Towards environmentally sustainable human behaviour: targeting nonconscious and conscious processes for effective and acceptable policies". Philosophical Transactions. Series A, Mathematical, Physical, and Engineering Sciences, 375: 1-12.

Milman, O., S. Leavenworth. 2016. "China's plan to cut meat consumption by $50 \%$ cheered by climate campaigners". The Guardian, 20 June, https:/www.theguardian.com/world/2016/ jun/20/chinas-meat-consumption-climate-change.

monteiro, C. A., et al. 2017. “The carnism inventory: measuring the ideology of eating animals". Appetite, 113: 51-62.

MORLEY, N. 2017. "Politicians in Denmark are going vegan to tackle climate change". Metro News, 18 May, http://metro.co.uk/2017/05/18/politicians-in-denmark-are-going-veganto-tackle-climate-change-6644947/.

NAGESh, A. 2016. "Denmark wants to tax meat to help combat climate change". Metro News, 27 April, http://metro.co.uk/2016/04/27/denmark-wants-to-tax-me at-to-help-combatclimate-change- $5845817 /$.

NATIONAL GEOGRAPHIC AND GLOBESCAN. 2014. "Greendex 2014: consumer choice and the environment - a worldwide tracking survey". http://images.nationalg eographic.com/wpf/ media-content/file/NGS_2014_Greendex_Highlights_FINA L-cb1411689730.pdf.

NUnEs, C., J. M. Pereira. 2016. “Os negócios da comida saudável”. Expresso, 3 February, http:// expresso.sapo.pt/economia/exame/2016-02-03-Os-negocios-da-comida-saudavel.

obenchain, J., A. Spark. 2016. Food Policy: Looking Forward From the Past. NY: CRC Press, Taylor \& Francis Group.

PAN (People - Animals - Nature) - Legislative proposal. n./d. "Inclusão da opção vegetaria na em todas as cantinas públicas". http://app.parlamento.pt/webutils/docs/doc.pdf?p ath $=6148523063446 \mathrm{f} 764 \mathrm{c} 3246795 \mathrm{a} 5868774 \mathrm{~d} 546 \mathrm{f}_{33} 4 \mathrm{e} 7 \mathrm{a} 67774 \mathrm{c} 336470626 \mathrm{~d} 6 \mathrm{c} 75615$

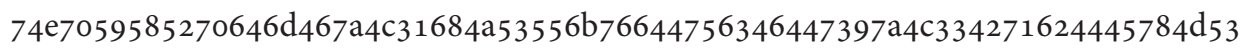
315953556c4a4c6d527659773d3d\&fich=pjl111-XIII.doc\&Inline=true.

PIRAges, D., P. R. Erhlich. 1974. Ark II: Social Response to Environmental Imperatives. San Francisco: W. H. Freeman.

RAUWALD, K. S., C. F. Moore. 2002. "Environmental attitudes as predictors of policy support across three countries". Environment and Behavior, 34 (6): 709-739.

RIDEOUT, B. 2005. "The effect of a brief environmental problems module on endorsement of the New Ecological Paradigm in college students". The Journal of Environmental Education, $37(1): 3-11$.

RIEK, B. M., E. W. Mania, and S. L. Gaertner. 2006. "Intergroup threat and outgroup attitudes: a meta-analytic review". Personality and Social Psychology Review, 10 (4): 336-353.

RUBY, M. B. 2012. "Vegetarianism: a blossoming field of study". Appetite, 58: 141-150.

SCHMIDT, L. et al. 2016. Primeiro Grande Inquérito sobre Sustentabilidade: Relatório Final. Lisbon:

Observa. Instituto de Ciências Sociais da Universidade de Lisboa/Missão Continente.

SMIL, V. 2002. "Eating meat: evolutions, patterns and consequences". Population and Development Review, 28 (4): 599-639.

SORON, D. 2010. "Sustainability, self-identity and the sociology of consumption". Sustainable Development, 18: 172-181.

STEHFest, E. et al. 2009. "Climate benefits of changing diet". Climatic Change, 95: 83-102.

STEINFELD, H. et al. 2006. Livestock's Long Shadow. Rome: FAO.

STEPHAN, W. S., C. W. Stephan. 2000. "An integrated threat theory of prejudice". In Reducing Prejudice and Discrimination, ed. S. Oskamp. Mahwah, NJ: Lawrence Erlbaum Associates, 
23-45.

STERN, P. C., T. Dietz, and G. A. Guagnano. 1995. “The new ecological paradigm in socialpsychological context”. Environmental and Behavior, 27 (6): 723-743.

truninger, M. 2010. O Campo Vem à Cidade: Agricultura Biológica, Mercado e Consumo Sustentável. Lisbon: Imprensa de Ciências Sociais.

UN General Assembly. 2015. "Transforming our world: The 2030 Agenda for Sustainable Development". http://www.refworld.org/docid/57b6eze44.html.

whitley, C., R. Gunderson, and M. Charters. 2017. "Public receptiveness to policies promoting plant-based diets: framing effects and social psychological and structural influences". Journal of Environmental Policy \& Planning, 10: 1-19.

ZAHRAN, S. et al. 2006. "Climate change vulnerability and policy support". Society \& Natural Resources, 19 (9): 771-789.

CARDOSO, S. G. et al. 2018. "Public support for vegetarian meals in public canteens: a preliminary study". In Changing Societies: Legacies and Challenges. Vol. III. The Diverse Worlds of Sustainability, eds. A. Delicado, N. Domingos and L. de Sousa. Lisbon: Imprensa de Ciências Sociais, 297-315. 